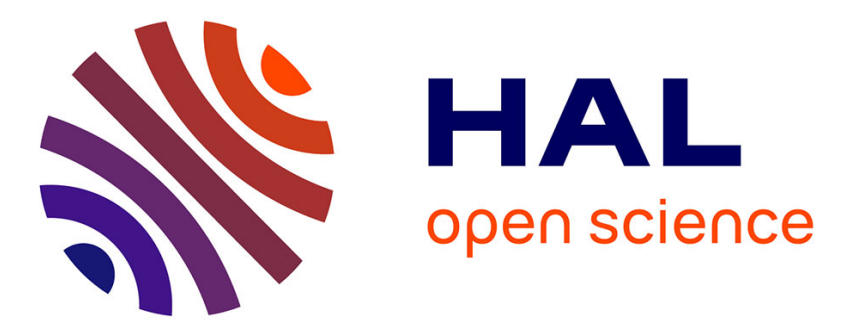

\title{
Stable self-assembly of dipolar molecules on an Au(111) surface under UHV and an inert-atmosphere
}

\author{
Irma Custovic, Damien Teyssieux, Judicaël Jeannoutot, Frank Palmino, \\ Frédéric Cherioux
}

\section{- To cite this version:}

Irma Custovic, Damien Teyssieux, Judicaël Jeannoutot, Frank Palmino, Frédéric Cherioux. Stable self-assembly of dipolar molecules on an $\mathrm{Au}(111)$ surface under UHV and an inert-atmosphere. Nanotechnology, 2020, 31 (10), pp.105601 (5). hal-02993763

\section{HAL Id: hal-02993763 https://hal.science/hal-02993763}

Submitted on 7 Nov 2020

HAL is a multi-disciplinary open access archive for the deposit and dissemination of scientific research documents, whether they are published or not. The documents may come from teaching and research institutions in France or abroad, or from public or private research centers.
L'archive ouverte pluridisciplinaire HAL, est destinée au dépôt et à la diffusion de documents scientifiques de niveau recherche, publiés ou non, émanant des établissements d'enseignement et de recherche français ou étrangers, des laboratoires publics ou privés. 


\title{
Stable self-assembly of dipolar molecules on an Au(111) surface under UHV and an inert- atmosphere
}

\author{
Irma Custovic ${ }^{1}$, Damien Teyssieux ${ }^{1}$, Judicael Jeannoutot ${ }^{1}$, Frank Palmino ${ }^{1}$ and \\ Frédéric Chérioux ${ }^{1}$ \\ ${ }^{1}$ Univ. Bourgogne Franche-Comte, FEMTO-ST, CNRS, UFC, 15B avenue des Montboucons, F-25030 \\ Besancon, France.
}

E-mail: frederic.cherioux@femto-st.fr

Received $\mathrm{xxxxxx}$

Accepted for publication $\mathrm{xxxxxx}$

Published xxxxxx

\begin{abstract}
The growth of extended supramolecular network by using dipolar molecules as building blocks is of great technological interest. We investigated the self-assembly of a dipolar molecule on an $\mathrm{Au}(111)$ surface. The formation of extended two-dimensional network was demonstrated by scanning tunnelling microscopy under ultra-high vacuum and explained in terms of moleculemolecule interactions. This 2D-network is still stable under pressure of one atmosphere of nitrogen, which demonstrated its interest for the development of submolecular-precisely polyfunctional smart surfaces.
\end{abstract}

Keywords: self-assembly, supramolecular network, STM, air-stability.

\section{Introduction}

The fabrication of perfectly ordered nanostructures, based on the controlled adsorption and self-assembly of organic molecules on surfaces, is deeply investigated, since the last two decades, due to their fundamental interest as well as their integration as active components in functional devices. ${ }^{1-5}$ In this context, dipolar molecules are of increasing interest since they possess a wide spectrum of appealing properties ${ }^{6-9}$ that could be applied in nanomaterials and nanodevices. Nevertheless, the adsorption of dipolar molecules on highlyoriented pyrolytic graphite (HOPG) ${ }^{10-11}$ and semi-conductive surfaces $^{12}$ prevalently leads to the formation of supramolecular networks with alignment (parallel or antiparallel) of the permanent dipole of molecules, while it is scarcely observed on metal surfaces ${ }^{13-14}$. Indeed, dipole-dipole interaction is often weaker than the other molecule-molecule or molecule-surface interactions that occur on metal surfaces. ${ }^{15}$ Therefore, it is important to circumvent the weakness of on-surface dipole-dipole interaction in order to provide a convenient strategy to achieve the formation of $2 \mathrm{D}$ periodic network based on dipolar molecules (especially) on metallic surfaces. In addition, the fabrication of the monolayered supramolecular self-assemblies achieved under ultra-high vacuum are rarely stable under ambient conditions, ${ }^{16}$ which strongly narrowed their appeal in terms of nanotechnologies. In this letter, we propose to investigate the development of 2D-extended supramolecular network with periodic arrangement of dipoles on an $\mathrm{Au}(111)$ surface by using molecules which possess functional groups which can be involved as electron donor or acceptor (for the dipole) and as donor or acceptor of Hydrogen bond (for the orientation). Thereby, we expect that dipole-dipole interaction and intermolecular interaction will be collaborative rather than competitive to achieve the formation of the expected periodic 2D-network. We report the growth of the extended 
supramolecular network of 1-(4"-cyanobiphenyl)-4-(4"methoxybiphenyl)-2,5-bis(decyloxy)benzene molecules by deposition at different molecular coverages on an $\mathrm{Au}(111)$ surface. On the basis of submolecular resolution of STM images, we have elucidated Hydrogen bond and van der Waals interactions as the driven forces for the self-assembling. In addition, we have demonstrated that supramolecular network of dipolar molecules is preserved even under exposition of one atmosphere of nitrogen pressure.

\section{Results and discussion}

\subsection{Description of the molecule}

1-(4"-cyanobiphenyl)-4-(4'’-methoxybiphenyl)-2,5bis(decyloxy)benzene (LdipCC) molecule is constituted by a methoxy group (the electron donor) and by a cyano group (the electron withdrawing) distanced by $2.7 \mathrm{~nm}$ corresponding to the length of the five phenyl rings (See Fig. 1). These features will assume a strong permanent dipole.

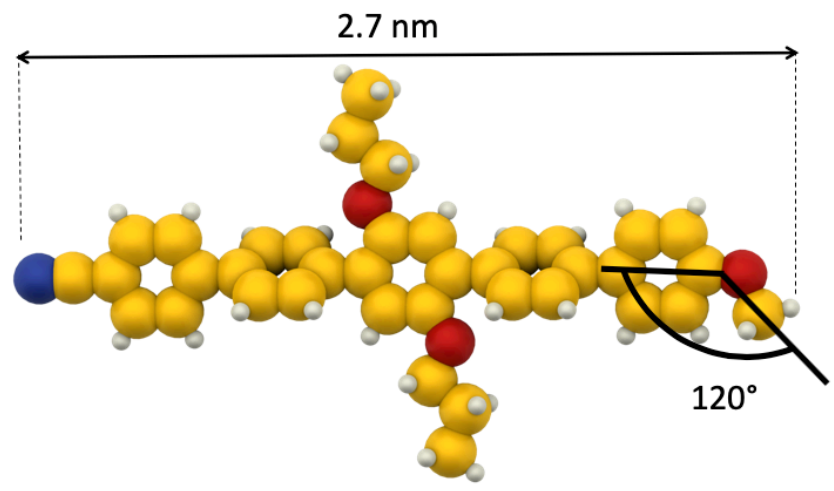

Figure 1. Representation of 1-(4"-cyanobiphenyl)-4-(4' 'methoxybiphenyl)-2,5-bis(decyloxy)benzene (LdipCC) molecule. Nitrogen atom: Blue, Oxygen atoms: red, Carbon atoms: yellow and Hydrogen atoms: white.

The permanent dipole moment of LdipCC is estimated to be around $4.5 \mathrm{D}$ by using semi-empirical computational method (Austin Model 1) included in Gaussian package. ${ }^{17}$ In addition, cyano group as well as methoxy group are well known as acceptor or donor/acceptor of Hydrogen bonds, respectively. ${ }^{18}$ In consequence, we expected that these groups can play a dual collaborative role: 1) assuming a strong permanent dipole, and 2) promoting intermolecular interaction to favour alignment of these dipoles on a metal surface. Eventually, we have added two short lateral alkyl chains constituted only by three carbon atoms linked to the central aromatic ring. Indeed, by using longer alkyl chains (up to 6 carbon atoms), strong van der Waals interaction would occur, ${ }^{4}$ which can be antagonist of the expected supramolecular orientation. However, the short alkyl chains still allow to keep the

solubility of LdipCC molecule (for the purification process). We synthesized LdipCC molecule in four steps by using well-known procedures (See ESI for synthetic procedure).

\subsection{Characterizations at sub-monolayer range by UHV- STM}

LDipCC molecules were deposited in a low coverage (0.3 monolayer) on the Au(111) surface. These molecules formed unorganised molecular structures (Fig. 2a). By increasing the molecular coverage of LdipCC molecules to 0.5 monolayer, a "porous-like" supramolecular network is being formed (Fig. 2b), surrounded by unorganised molecules. On the basis of the highresolution STM images (Fig. 2c), where cyano group can be slightly distinguished from the methoxy group, we proposed a model for the supramolecular organization. This model, described in. Fig. 2d, is mainly governed by dominative Hydrogen bond between cyano groups and $\mathrm{H}$ atom of phenyl rings ${ }^{18}$ and van der Waals interaction between interdigitated alkyl chains (highlighted by dashed white rectangle in Fig. 2d).,19 The distance between nitrogen atom of cyano group and $\mathrm{H}$ atom of phenyl ring (dashed white ellipse, inset of Fig. 2d). is $0.39 \mathrm{~nm}$. In addition, the distances between nitrogen atom of cyano group and two $\mathrm{H}$ atoms, one being of a phenyl ring and the other one from methoxy group (double white ellipse, inset of Fig. 2d), are $0.22 \mathrm{~nm}$ (i. e. three centred Hydrogen bond). ${ }^{18}$ Both distances are in agreement with the presence of Hydrogen bond. ${ }^{18}$

a)

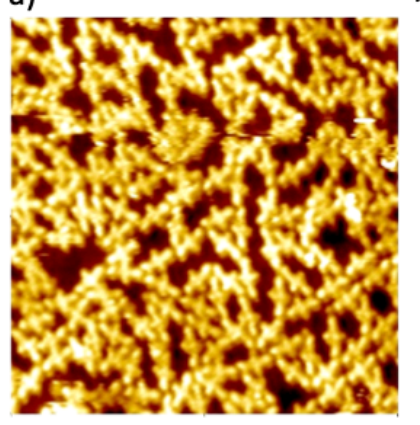

c)

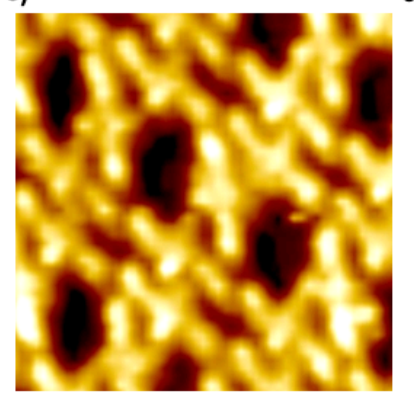

b)

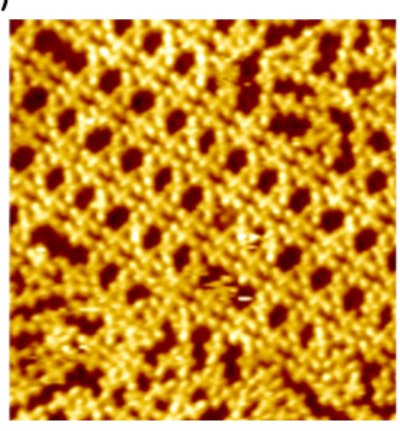

d)

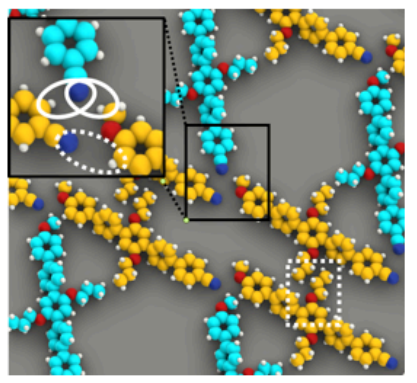


Figure 2. (a) STM image of $\operatorname{LdipCC} / \mathrm{Au}(111)$ with a coverage of 0.3 monolayer $\left(30 \times 30 \mathrm{~nm}^{2}\right), \mathrm{V}_{\mathrm{S}}=-1.9 \mathrm{~V}, \mathrm{I}_{\mathrm{t}}=$ $10 \mathrm{pA}, 110 \mathrm{~K})$. (b) STM image of LdipCC/Au(111) with a coverage of 0.5 monolayer $\left(30 \times 30 \mathrm{~nm}^{2}, \mathrm{~V}_{\mathrm{S}}=-1.8 \mathrm{~V}, \mathrm{I}_{\mathrm{t}}=\right.$ 10 pA, $110 \mathrm{~K})$. (c) High-resolution STM image $(9.3 \times 9.7$ $\left.\mathrm{nm}^{2}, \mathrm{~V}_{\mathrm{S}}=-1.8 \mathrm{~V}, \mathrm{I}_{\mathrm{t}}=10 \mathrm{pA}, 110 \mathrm{~K}\right)$ of LdipCC/Au(111) for a coverage of 0.5 monolayer. (d) Proposed molecular model of the LdipCC adlayer shown in (c). Vertical LdipCC molecules are highlighted in blue in the adsorption model. The white dashed rectangle highlights the van der Waals interaction between two interdigitated alkyl chains. In the insert, the white dashed ellipse surrounds the Hydrogen bonds between two consecutive molecules involved in the double rows. The double white ellipse highlights the three-centred Hydrogen bond between one nitrogen atom of a cyano group and two $\mathrm{H}$ atoms of two adjacent molecules.

\subsection{Characterizations at monolayer range by UHV-STM}

The molecular deposition was increased in order to reach the monolayer range. Fig. 3 (and a larger scale image, Fig S5 in ESI) corresponds to an experimental STM image of one monolayer coverage of LdipCC deposited onto $\mathrm{Au}(111)$ surface at room temperature under UHV condition and scanned at $110 \mathrm{~K}$. The LdipCC molecules assemble into compact two-dimensional network. This supramolecular network consists fused periodic domains, bordered by grain boundaries (black dashed lines in Fig. 3).

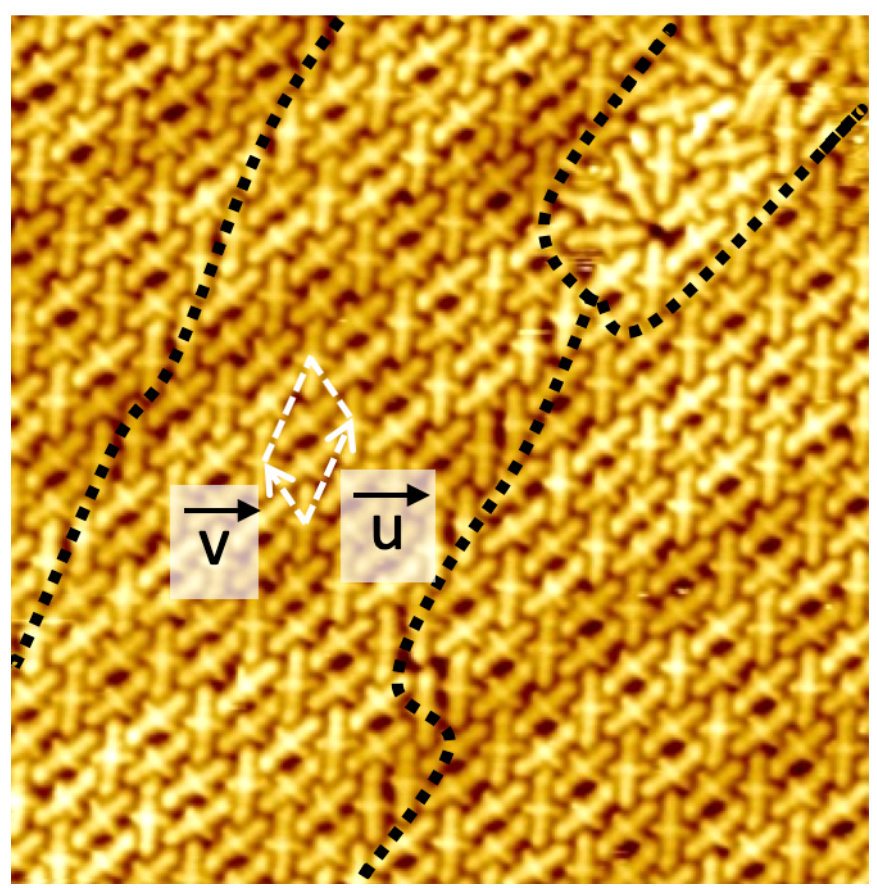

Figure 3. STM image of a monolayer of LdipCC deposited on an $\mathrm{Au}(111)$ surface with submolecular resolution on each molecule $\left(30 \times 30 \mathrm{~nm}^{2}\right) V_{\mathrm{S}}=-1.9 \mathrm{~V}$, $\left.I_{\mathrm{t}}=10 \mathrm{pA}, 110 \mathrm{~K}\right)$. Black lines surround the periodic domains of LdipCC/Au(111). $\overrightarrow{\boldsymbol{u}}$ and $\overrightarrow{\boldsymbol{v}}$ are the vectors that describe the unit cell of the network.

Each periodic domain is built by the repetition of an unit cell with a parallelogram shape (vectors: $\overrightarrow{\boldsymbol{u}}$ and $\overrightarrow{\boldsymbol{v}}$ with $|\overrightarrow{\boldsymbol{u}}|=3.57 \mathrm{~nm}$ and $|\overrightarrow{\boldsymbol{v}}|=2.47 \mathrm{~nm}$, corresponding to an area of $7.05 \mathrm{~nm}^{2}$ ). In each unit cell, three bright features showing a cross-shape with a length of $2.7 \mathrm{~nm}$ are observed. These cross-shaped features are ended by a small elbow with an angle of $120^{\circ}$ (Fig. 4a).

On the basis of analysis of STM images, we attribute each cross-shaped feature to a LdipCC molecule (Fig. 4b). There are three LdipCC molecules per unit cell, for an area of $7.05 \mathrm{~nm}^{2}$. Therefore, the molecular density is 2.3 molecules per $\mathrm{nm}^{2}$.
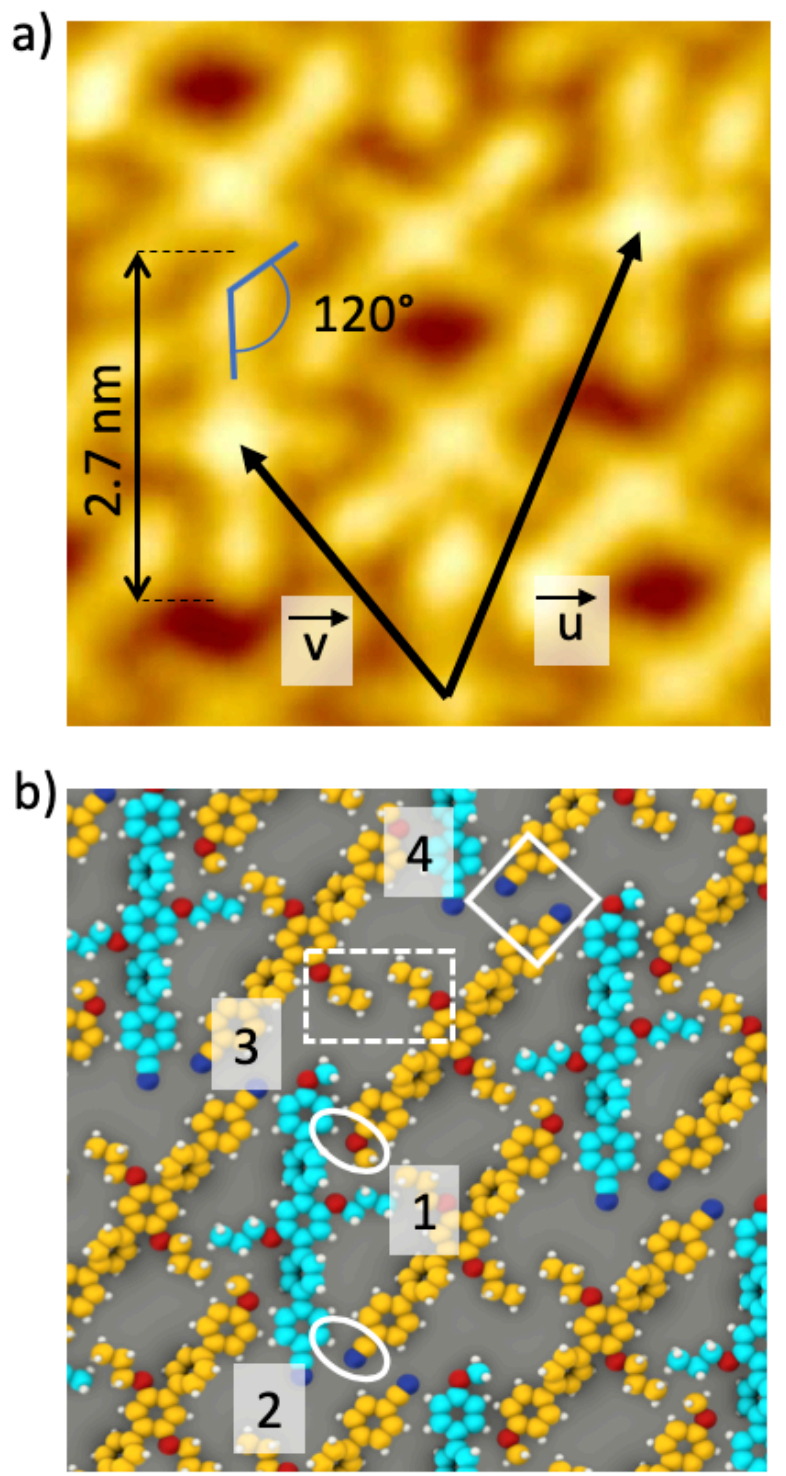
Figure 4. (a) High-resolution $\mathrm{STM}$ image $\left(6 \times 6 \mathrm{~nm}^{2}, V_{\mathrm{S}}=\right.$ $\left.1.0 \mathrm{~V}, I_{\mathrm{t}}=10 \mathrm{pA}, 110 \mathrm{~K}\right) \mathrm{LdipCC} / \mathrm{Au}(111) . \overrightarrow{\boldsymbol{u}}$ and $\overrightarrow{\boldsymbol{v}}$ are the vectors that describe the unit cell of the network. (b) Proposed molecular model of the LdipCC adlayer. Vertical LdipCC molecules are highlighted in blue in the adsorption model. The white ellipses surround the Hydrogen bonds of the type $\mathrm{CH} \cdots \mathrm{O}$ (labelled with 1) and $\mathrm{CH} \cdots \mathrm{N}$ (labelled with 2 ) between molecules. The white dashed rectangle (labelled with 3 ) highlights the van der Waals interaction between two interdigitated alkyl chains. The white square (labelled 4) surrounds the two Hydrogen bonds between two cyanophenyl moieties of two aligned molecules.

The model of the molecular arrangement of LdipCC adsorbed on an Au(111) surface is described in Fig 4b. An elemental cell is constituted by two parallel molecules (highlighted in yellow) and a third molecule (in blue, Fig 4b) rotated $60^{\circ}$ with respect to the other two molecules. The intermolecular interactions originate from the interdigitation of alkyl chains (labelled 3 in Fig. 4b), Hydrogen bond between two cyanophenyl groups (labelled 4 in Fig. 4b), Hydrogen bond between $\mathrm{C}-\mathrm{H}$ of aromatic groups and nitrogen atom of cyano group (labelled 4 in Fig. 4b), or oxygen atom of methoxy group (labelled 1 in Fig. 4b), respectively. The distance between nitrogen atom of cyano moieties and $\mathrm{H}$ atoms of phenyl rings (labelled 4 in Fig. 4b) is $0.29 \mathrm{~nm}$, which is in agreement with the presence of a Hydrogen bond. Moreover, nitrogen atom of cyano moiety and $\mathrm{H}$ atom of phenyl ring and oxygen atom of methoxy moiety and $\mathrm{H}$ atom of phenyl ring (labelled 1 and 2 in Fig. 4b) are distanced from $0.2 \mathrm{~nm}$. All these distances are in accordance with Hydrogen bond. In this model, the LdipCC molecules highlighted in blue in Fig. 4b could also adopt another orientation, corresponding to a rotation by $180^{\circ}$ (see Fig. S6 in ESI), as observed in Fig 3. In this case, supramolecular interactions are identical to those leading to model described in Fig. 4b, justifying why these two conformations are randomly observed.

\subsection{Stability at 1 atmosphere}

As Au (111) surface is well-known to be inert under ambient conditions, we have checked the stability of LdipCC/Au(111) interface under these conditions. The LdipCC/Au(111) interface was exposited to 1 bar of nitrogen pressure during $5 \mathrm{~min}$ at room temperature. Then, the sample is introduced in UHV without further treatment (thermal annealing etc.) and scanned by STM at room temperature.

The corresponding STM image is shown in Fig. 5. The cross-shape of each LdipCC molecule is still visible. The comparison of the STM images in Fig. 3 and Fig. 5b shows that the area of the domains is not modified either by this exposure to nitrogen. The supramolecular arrangement observed previously is robust enough to overcome the exposition under nitrogen pressure of 1 bar. Indeed, vectors: $\overrightarrow{\boldsymbol{u}}(|\overrightarrow{\boldsymbol{u}}|=3.57 \mathrm{~nm})$ and and $\overrightarrow{\boldsymbol{v}}(|\overrightarrow{\boldsymbol{v}}|=2.47$ $\mathrm{nm}$ ), still describe the unit cell of the network (See Fig 5a).

a)

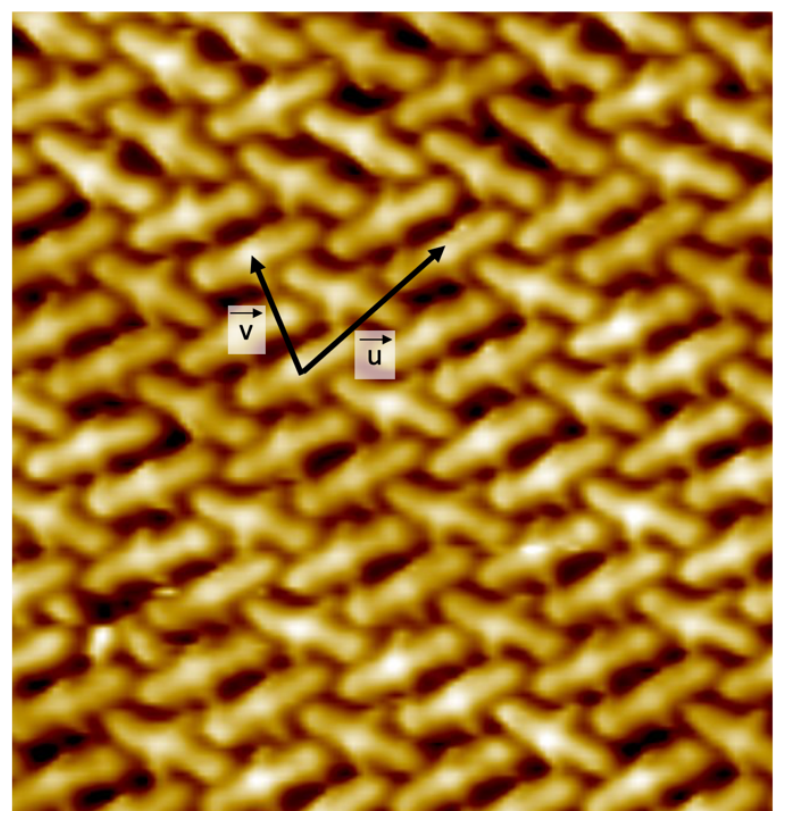

b)

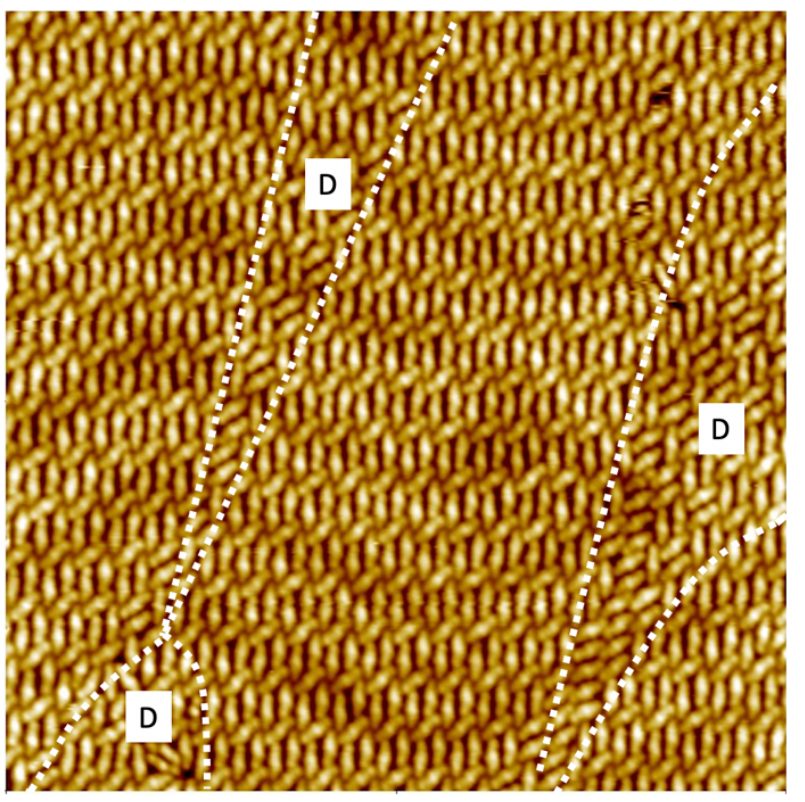

Figure 5. STM images of a monolayer of LdipCC molecules deposited on an $\mathrm{Au}(111)$ surface and recorded after exposition to a nitrogen pressure of 1 bar. (a) Highresolution image $\left(15 \times 15 \mathrm{~nm}^{2}, \mathrm{~V}_{\mathrm{S}}=-0.6 \mathrm{~V}, \mathrm{I}_{\mathrm{t}}=10 \mathrm{pA}\right.$, $300 \mathrm{~K})$ showing that supramolecular organization is preserved, as highlighted by $\overrightarrow{\boldsymbol{u}}$ and $\overrightarrow{\boldsymbol{v}}$ are the vectors. (b) 
Large-scale STM image $\left(50 \times 50 \mathrm{~nm}^{2}, \mathrm{~V}_{\mathrm{S}}=-1.1 \mathrm{~V}, \mathrm{I}_{\mathrm{t}}=7\right.$ $\mathrm{pA}, 300 \mathrm{~K}$ ) showing that the size of the domains is not modified after nitrogen exposure. The three domains Dlabelled correspond to disordered area.

On the $\mathrm{Au}(111)$ surface, the dipole-dipole interaction cannot be outstandingly dominate force for the selfassembly, even if LdipCC molecules exhibit a strong permanent dipole moment. On the $\mathrm{Au}(111)$ surface, the main driving forces are Hydrogen bond and van der Waals interactions that dominantly influence the selfassembly even at low molecular coverage. Nevertheless, molecule-molecule interactions are strong enough to support the stability of supramolecular network while it is exposed to 1 bar of nitrogen pressure.

\section{Conclusion}

In summary, we have investigated the growth of a supramolecular network on the basis of dipolar molecules deposited on an $\operatorname{Au}(111)$ surface. These dipolar molecules are self-assembled into compact, twodimensional network. Hydrogen bond and van der Waals interaction are the main driven force of the formation of the supramolecular network. However, despite of their directionality and their strength, Hydrogen bonds were not efficient to promote a periodic arrangement of aligned dipoles, indicating that expected collaborative effect between intermolecular interaction and dipole-dipole interaction is not enough strong. Yet, this network is still stable under one atmosphere of nitrogen. The preservation of robustness and stability of supramolecular network under inert-atmosphere is of high interest for the integration of hybrid organic-inorganic devices in nanoelectronics.

\section{Acknowledgements}

This work was supported by a grant from the Agence National de la Recherche (ACTION, ANR-15-CE29-0005) and a grant from the Pays de Montbéliard Agglomération.

\section{References}

[1] Bartels L 2010 Nature Chem. 287

[2] Clair S and de Oteyza D G 2019 Chem. Rev. 1194717

[3] Barth J V 2007 Ann. Rev. Phys. Chem. 58375

[4] Elemans J A A W, Lei S and De Feyter S. 2009 Angew. Chem. Int. Ed. 487298

[5] Makoudi Y, Jeannoutot J, Palmino F, Chérioux F, Copie G, Krzeminski C, Cleri F. and Grandidier B 2017 Surf. Sci. Rep. 72316

[6] Bairagi K, Bellec A and Chumakov R.G., 2015 Surf. Sci. 641248

[7] Tayi A, Kaeser A and Matsumoto M 2015 Nat. Chem. 7281

[8] Kimura S 2008 Org. Biomol. Chem. 61143
[9] Novotny L, Beversluis and Youngworth K S 2001 Phys. Rev. Lett. 865251

[10] Xu L, Miao X, Ying X and Deng W 2012 J. Phys. Chem. C 1161061

[11] Wang Y, Jiao T-F, Zhang Z-H, Chen T, Liu M-H, Wan L-J and Wang D 2013 J. Phys. Chem. C 11716392

[12] Harikumar K R, Lim T, McNab I R , Polanyi J C, Zotti L, Ayissi S and Hofer W A 2008, Nature Nanotechnol. 3222

[13] Liu X, Wei Y and Reutt-Robey J E 2014 J. Phys. Chem. C 118 3523

[14] Baber A E, Jensen S C and Sykes E C H 2007 J. Am. Chem. Soc. 1296368

[15] Kunkel D A, Hooper J, Simpson S, Miller D P , Routaboul L, Braunstein P, Doudin B, Beniwal S, Dowben P, Skomski R, Zurek E and Enders A 2015 J. Chem. Phys. 142101921

[16] Deshpande A, Sham C-H, Alaboson J M P, Mullin J M, Schatz G C and Hersam M C 2012 J. Am. Chem. Soc. 13416759

[17] Gaussian 09, Revision A.02, Frisch M J, Trucks G W, Schlegel H B, Scuseria G E, Robb M A, Cheeseman J R, Scalmani G, Barone V, Petersson G A, Nakatsuji H, Li X, Caricato M, Marenich A, Bloino J, Janesko B G, Gomperts R, Mennucci B, Hratchian H P, Ortiz J V, Izmaylov A F, Sonnenberg J L, Williams-Young D, Ding F, Lipparini F, Egidi F, Goings J, Peng B, Petrone A, Henderson T, Ranasinghe D, Zakrzewski V G, Gao J, Rega N, Zheng G, Liang W, Hada M, Ehara M, Toyota K, Fukuda R, Hasegawa J, Ishida M, Nakajima T, Honda Y, Kitao O, Nakai H, Vreven T, Throssell K, Montgomery J A, Jr., Peralta J E, Ogliaro F, Bearpark M, Heyd J J, Brothers E, Kudin K N, Staroverov V N, Keith T, Kobayashi R, Normand J, Raghavachari K, Rendell A, Burant J C, Iyengar S S, Tomasi J, Cossi M, Millam J M, Klene M, Adamo C, Cammi R, Ochterski J W, Martin R L, Morokuma K, Farkas O, Foresman J B, and Fox D J, Gaussian, Inc., Wallingford CT, 2016.

[18] Steiner T 2002 Angew. Chem. Int. Ed. 4148

[19] Bléger D, Kreher D, Mathevet F, Attias A-J, Schull G, Huard A, Douillard L, Fiorini-Debuischert C and Charra F 2007 Angew. Chem. Int. Ed. 467404 